cesin that way, and instead would be referred to as Tanakasensei. The term "sensei" is an honorific accorded to teachers, with a meaning transcending that of professor. It has been suggested that if a Japanese prime minister were to meet a former teacher, it is the former student who would bow low as a matter of acknowledging his proper place. The prime minister might later tell someone about having met his onsbi, a word translated in the dictionary as "former teacher" that also connotes a person to whom one owes a debt that can never be fully repaid. Sensei, then, is not only a person of wisdom but also a major actor in the intricate web of obligations, group memberships, and dependencies that defineJapanese social life and culture. To take the role of sensei does not necessarily imply the creation of valid knowledge even though it requires the "publication" of "research," nor does it necessarily presume an obligation to contribute to student learning even though it may require the holding of classes. To maintain status as sensei requires membership in a group identified hy some specialized research commitment, active involvement in activities that separate those inside the group from those outside it, the placement of students in jobs, and the sponsorship of those with academic ambitions into family-like academic cliques.

The ways in which faculty construct their roles may have major effects on critical public policy. Japan is now considering reforms at the university level explicitly based on U.S. practices. The changes being advocated include, among others, the development of interdisciplinarycourses, the establishment of credit transfer systems, the preparation of course syllabi, the recognition of the concept of faculty development, the use of student course evaluations, and the appointment of faculty to contracts rather than tenure. More generally, universities are being told to create self-monitoring and self-evaluation systems for both teaching and research, to publicly report the results of these systems, and to individualize and diversify their programs. Most of the changes being advocated are consistent with the values of US . professional culture but run counter to current institutional practice in Japan as well as to deeply held national cultural values. In contrast, many reforms currently being proposed for US . institutions may be consistent with national cultural values but inconsistent with U.S. professional culture. In both settings, viewing higher education from a cultural perspective may help us understand why our systems function as they do, and create more realistic expectations about both the costs and benefits of proposed improvements.

\section{Chinese Higher Education Reconsidered from the U.S. Experience}

\section{Min Weifang and Chen Xiangming \\ Mio Weifang is vice president of Peking University, Beijing, Chino. Chen Xiangming is associate professor in the Institute of Higher Education, Peking University. Address: Institute of Higher Education, Peking Univer- sity, Beijing 100871, China. Fax: 86-1-256-4095.}

$I^{1}$ $\mathrm{n}$ the past six months we have twice visited the United States to look at developments in American higher education in order to draw lessons for the current reforms in Chinese higher education. These visits, short as they were, helped us to get a better understanding of U.S.higher education, which in turn shed light on many of the issues we have been wrestling with in China. In this article, we offer some reflections on aspects of American higher education that we find relevant and useful in the Chinese context.

\section{THE PYRAMID STRUCTURE}

The U.S. higher education system, the biggest system in the world, basicallyreflects the requirements of the United States job market. The demand for human resources manifests itself in a pyramid structure, with a large number of institutions that train the general labor force at the bottom and a smaller number of research institutions that produce advanced specialistsat the top. In contrast to the U.S. structure, the Chinese counterpart before the 1980s could be viewed as a small inverted pyramid. There were more university-level students than technical/vocational students.

With the transformation from a centrally planned economy to a socialist market economy since the 1980s, the inverted pyramid is now in the process of being overturned. By 1994, out of the 1,080 regular higher learning institutions, 453 were short-cycle institutions with an enrollment of 1.3 million. The rest were teacher training institutions with an enrollment of 1.5 million undergraduate and 127,935 graduatestudents. By 1995, 1,156 adult higher education institutions had been established with an enrollment of 2.57 million students. This figure does not include the annual 100,000 graduates with a diploma obtained through self-study. In addition, over 800 nonstate postsecondary institutions have been created.

However, the percentage of university students in the population is still only 0.44 . With rising living standards, parents' high expectations for their only child, and the cultural value placed on school learning, the demand for higher education in China far exceeds the current capacity of the institutions. 


\section{THE DECENTRALIZATION OF ADMINISTRATION}

During our travels in the United States, we were struck by its decentralized system. The federal govemment gives a great deal of autonomy to the states and institutions of higher learning, ensuring equal access, fair handling of student aid programs, and protechon of certain fields of study through legislation, financial support, and research contracts. China has much to learn from the U.S. experience in this regard. Before the 1980s, Chinese higher education, like everything else in the country, was highly centralized and tightly controlled by the government. Worse still, the institutions were sponsored by three independent parties: the State Education Commission, the central ministries, and the local authorities. This overlapping system resulted in lack of communication and cooperation between the central and local govemments, which led to a surplus number of single-field institutions, redundancy of specialties and institutions, overly narrow fields of study, waste and misuse of already scarce resources, narrowly trained personnel, and lack of initiatives on the part of institutions and faculty.

Since the 1980 s, the central government has been giving greater latitude to local authorities and institutions. At present, an institution has the right to choose its own specialties, decide its own student enrollment, and appoint faculty. The job market for graduates is currently managed through mutual negotiations between employers and graduates. The three sponsors of higher education have been working together to run a more efficient and effective educational enterprise. The central government takes care of institutions that have a leading position in the national landscape, focus on a certain profession, or are difficult to manage by one locality. All the rest are taken care of hy local authorities.

\section{MOBILIZATION OF RESOURCES}

The problem of financial constraints is shared by all the U.S institutions we visited. Because of the economic austerity and the end of the Cold War, both federal and state funds are shrinking as a proportion of university budgets. As a result, universities have to resort to various means to raise funds. Chinese universities are facing even more serious financial constraints, indicated by low teacher salaries, shortage of funds for instructional expenses, and declining subscriptions to academic journals. Since government allocations to higher education have been declining proportionally, universities have been diversifymgfunding sources, including implementation of cost-sharing and cost-recovery policies. Since 1989, for the first time in 40 years, institutions began to experiment with charging tuition and fees from students. The long-standing notion of free higher education has become so deeply entrenched in China that it is very difficult for people to accept paying for education both financially and psychologically. To alleviatethis problem, some universities have set up work-study programs for poor students, and the government is giving scholarships and loans to students in need.

CONCERNS OVER THE QUALITY OF UNDERGRADUATEEDUCATION Many U.S. scholars we encountered expressed their great concern over the quality of undergraduate education. In China, we face similar problems of lowering admission standards to attract students to some institutions (especially private ones), and inadequate teaching quality due to undue emphasis on research in some top universities. In addition, other problems loom large on the horizon. Because of the heavy influence of the former Soviet Union, the narrowly defined fields of study have produced short-sighted students both in knowledge and skills, and the curriculum still does not allow much room for individual differences and interdisciplinary learning. Recently, many Chinese institutions have been cutting obsolete and redundant specialties, merging related ones, expanding applied programs, and creating interdisciplinary fields of study.

During our trips many U.S. educators talked about learning from the cooperative spirit of Chinese culture. In our discussions, we heard the view expressed that, in addition to knowledge and skills, undergraduate education should develop a good attitude in students for interpersonal cooperation and social responsibility, which is thought to he one of the successful aspects of Chinese education. These comments made us rethink our own cultural tradition and the present situation in China. Traditionally, Chinese culture is a group-oriented one in which students are encouraged to help each other in learning.

However, as the economic reforms progress, competition and an emphasis on achievement have taken hold among Chinese students, who have become more and more individualistic - like their U.S. counterparts. As they compete with each other for entrance to the few formal institutions, they have gradually lost the tradition of friendly cooperation. Ironically and sadly, what our U.S. colleagues sing praises of is exactly what we are losing in China. Recently, Chinese educators have been engaged in a heated discussion on how to improve students' suzhi (quality), in order to prevent students from losing their sense of moral responsibility, humanistic concerns, and Chinese cultural traditions. 